\title{
THE LABORATORY OF THE DEPARTMENT OF ROMANCE LANGUAGES AT MICHIGAN
}

\author{
LAWRENCE B. KIDDLE \\ University of Michigan
}

A room where equipment is available for practice work in foreign languages either for self-instruction or for supervised group study is of great value in supplementing the exercises of the modern language classroom. Such a place with its proper equipment is known as a language laboratory and in this laboratory primary emphasis is placed on the opportunities offered for oral and aural work. The laboratory may be used by language students at all levels from the beginner to the advanced student of literature, phonetics and dialectology. It also should be open for the casual adult learner as a means for self-help in language study or for refreshing the knowledge of a language already studied.

The type of language laboratory described above was established in September 1949 by the department of Romance Languages at the University of Michigan. Since it is our hope that this laboratory will eventually form the nucleus of a larger establishment open to all students of foreign languages on the campus of the University, it seems fitting that a description of our first year's experience should be prepared.

The present laboratory is a lineal descendant of two previous laboratories planned and supervised by the present writer. The first of these began to function in the Training Division of the U.S. Navy Department in September 1943 and the second, established in the Peruvian Naval Academy at Callao, Peru, was first used in July 1945. Each successive laboratory has been characterized by improvements both in equipment and in use. In September 1947, a suggestion was made that the department of Romance Languages establish a laboratory or practice room. The chairman of the department named a committee to study the proposal and, under the 


\section{LAWRENCE B. KIDDLE}

supervision of this committee, equipment was acquired and the laboratory was opened for student use at the beginning of the Fall semester 1949.

This article will present a brief description of the laboratory, its equipment, its use by the special oral sections in French and Spanish, and its value in the opinion of both students and teachers.

The laboratory is located in South Wing, University Hall, in a large room on the first floor. There is ample space for the six listening posts now in use and for limited future expansion. The listening posts are located on a long shelf-like table with electrical wall outlets for each post. There are no partitions between the individual listening spaces. At each post there is a Knight Language Master available for the student's use. The laboratory provides, in addition, in adjoining classrooms, playback equipment for individual or group listenIng. There is also in the laboratory itself a recording suite consisting of the equipment room and a soundproofed room. In this section all our recording of class exercises is done.

The basic piece of equipment acquired for the laboratory is known as a Knight Language Master.* This machine, shown in the illustration that accompanies this article, consists of a dual speed turntable (33 1/3 and 78 r.p.m.) on which the student places a recording of his lesson. This recording has been made by the laboratory staff and on it the student hears the voice of a native speaker of French or Spanish. The voice repeats the day's lesson in breath-groups and allows repetition time for the student. The student adjusts the microphone so as to blend his voice with that of the speaker on the records and then begins to study orally his assignment by repeating after the voice on the record. This whole process is preserved by means of a wire re zorder that is an integral part of the machine. After the student has finished his lesson, he plays it back so that he can note his mistakes. The wirr with

- This machine is manufactured by the Alled Radio Corporation, $833 \mathrm{~W}$. Jackson Blvd., Chicago 7, Ilinois. The ancestor of the present machine was designed by Professor A. S. Hayes for use at the University of Loulsiana. The only important innovation is the addition of a wire recorder. Cf. Hispania, XXXII, 1 (Feb. 1949), 20-26. 


\section{LABORATORY AT MICHIGAN}

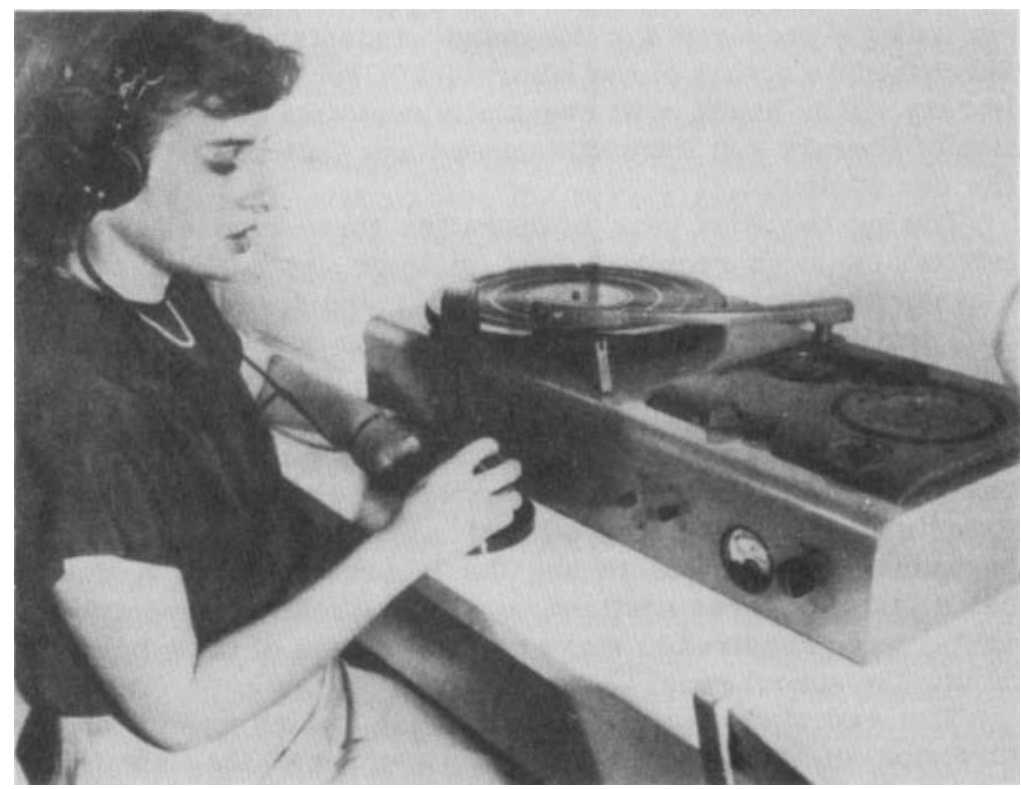

The Knight Language Master

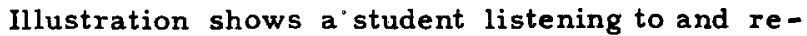
peating her language lesson. The whole procedure is recorded on the wire-recorder that forms an integral part of the machine.

the student's voice on it can be checked later by the instructor, who then consults with the student concerning his mistakes.

The laboratory as presently constituted has siz Knight Language Masters although plans for extended use by departmental students in the school year 1950-51 will require additional equipment.

Through a loan by the University Extension Service, the department was able to use a Presto-type recorder which has been used for making most of the recordings used by French 
and Spanish classes during the past year. Many commercial recordings prepared for language students have also been purchased as a part of the laboratory's record library. This library, it is hoped, will eventually contain a valuable collection of literary and linguistic recordings that will be available for our students.

During the first year of operation three classes used the laboratory as a required part of their instruction. These classes were known as "experimental" and "semi-experimental" sections since the aims and methods were characterized by being completely unlike the so-called traditional course (grainmar-translation) in the case of the former and only in part unlike that course in the case of the latter. There was one Spanish class in each category but in French only a semiexperimental section was offered. Other students of the department were invited to use the laboratory on a voluntary basis but only three sections, or approximately seventy students, were required to make continuous use of the laboratory during the school year.

The experimental course in Spanish, which was under the direction of the author of this article, used the laboratory equipment for group practice work in small drill sections during the first semester. During the second semester the students had regular weekly assignments to be recorded on individual spools of wire. These recordings were corrected in class and the student received a grade for his work. While this method of using the laboratory needs improvement, the student at least was aware that his pronunciation was constantly under observation. The classwork of this section was almost exclusively oral in nature, being based on Treviño, Spoken Spanish, for the most part. In order not to penalize the student of the experimental course as far as the required reading for elementary Spanish was concerned, the class did the same amount of reading as the other classes. The experimental class met three hours per week as a complete class and two additional hours per week in two drill sections of ten students each. This meant five contact hours per student, of which two were in small special groups.

The semi-experimental classes in French and Spanish 


\section{LABORATORY AT MICHIGAN}

used the same textbooks as the traditional classes: Pargment, Initiation à la Langue Française, and Barlow, Basic Oral Spanish. These classes met four hours each week just as did the traditional elementary classes. In addition, however, the students used recordings of their lessons and approximately one hour of their preparation for each class was done in the laboratory. As a result, these classes made more continuous use of the laboratory and its equipment than did the experimental class in Spanish. The recordings prepared by the laboratory staff consisted of the reading selection of the lesson recorded with pauses for repetition, questions and answers based on exercises in the text and, frequently, the "correct" versions of several English to Spanish composition exercises from the text to be translated by the student. This proved to be an added attraction of the laboratory in the opinion of the students.

The students reacted enthusiastically to the advantages of the laboratory, and during the school year they made use of its equipment in steadily increasing numbers. The popularity of the laboratory made a full-time attendant and technician necessary since adequate supervision could not be given by volunteers from the teaching staff of the department. At the end of the Spring semester, 1950, the students of the experimental and semi-experimental Spanish sections were asked to comment anonymously on the value of the laboratory as a part of their instruction. There were no adverse comments. In fact, the students unanimously approved the laboratory and its equipment and urged that more use be made of it in the future.

The instructors in charge of the oral sections (Ernst Pulgram in French; Charles $N$. Staubach and the present writer in Spanish) agree in their belief that the laboratory proved beneficial to the students in their classes. No objective testing program was undertaken to evaluate the work of the elementary students in French and Spanish since we had no desire to duplicate the apparently complete evaluation now being carried on by Wayne University. The following points, then, are a synthesis of the impressions of three experienced modern language teachers: 


\section{LAWRENCE B. KIDDLE}

1. Class time devoted to pronunciation and drills on pronunciation was considerably lessened and, despite this, the quality of the pronunciation of the students was better than that of classes previously taught by the same instructors. The time saved in this way was available for oral-aural drills of varied types or for other class exercises.

2. Students that ordinarily would have heard and used the foreign language only in the classroom were able to hear and repeat the lessons and exercises as often as they wished.

3. With a minimum amount of instruction in phonetics, even the slower and less gifted students were able to master a highly acceptable pronunciation.

4. Both the teacher and the student noted a heightened morale in the classes. Both felt that more of the foreign language was being learned and being taught than would have been possible without the laboratory. This, in itself, justifies the laboratory as an adjunct to home study.

5. With the gain in oral-aural proficiency, there was no apparent loss in reading ability. All classes read the same reading texts and, in the final written examination, did, at least, as well as the traditional classes. Here there is a need for a carefully planned and efficient testing program since there are many proponents of the oral-aural approach who believe that students will read better with that method than with the traditional methodology.

Many inquiries and requests for advice have come to the department of Romance Languages from other institutions interested in establishing a laboratory with electronic equipment similar to the one at Michigan. The closing paragraphs of this note are devoted to suggestions, born of our experience, for those who may be interested in language laboratories.

The equipment used by the student should be simple in operation and all students should be instructed in its use. The 


\section{LABORATORY AT MICHIGAN}

instruction can be given in orientation visits to the laboratory in regular class periods during the first week of classes of each semester. Our experience has shown that the average student can learn to use efficiently the Knight Language Master with its somewhat complicated wire recorder.

The laboratory must have a full-time attendant. Our experience with part-time assistants and with voluntary attendants from the teaching staff has been generally unsatisfactory. The full-time attendant should be familiar with the care and maintenance of electronic equipment since minor repairs and adjustments are constantly required. The attendant, also, must be able to instruct and assist the laboratory visitor in the proper use of the equipment. For this purpose, it is not necessary to know a foreign language since we refer here primarily to the mechanical aspects of operating an electronic device.

The laboratory should normally be as quiet as possible. It is, perhaps, desirable to have partitions separating the listening posts but, according to our experience, students repeating the foreign language and using earphones do not interfere with each other.

The laboratory should be available for all interested students and faculty and, for that purpose, should have both day and evening hours. The present writer's experience with previous laboratories has convinced him that the casual student of foreign languages (e.g., a faculty colleague from a department of Social or Natural Sciences) not only is an efficient user of a language laboratory but his sincere graditude makes him an enthusiastic supporter of the language teacher's efforts to improve instruction.

Our present-day world demands linguistic competence of constantly increasing numbers of our fellow citizens. The language laboratory, by providing an efficient way to supplement the work of the classroom and by giving the highlymotivated learner a means to advance at his own pace, offers language teachers an important new medium for achieving our goal: the steady improvement of modern language teaching. 